\title{
Constructive Cognition as Positive Behaviour
}

\author{
Lipi Mukhopadhyay \\ Indian Institute of Public Administration, New Delhi, India
}

\begin{abstract}
Emotion and cognition are inter-related variable influenced by environment and individual constructive ability. Review of researches done in this area would help in understanding of emotional bearing and influence on human behaviour. This is intended to explore in the present paper. Emotion plays an important role in constructive cognition. It is found that academic goal pursuit among young adolescents depends much on their emotional intelligence and adaptive skills. How one finds the immediate environment as supportive or oppressive will depend on the individual constructive cognition and influence future actions in dealing with the situation. Recent years, it has witnessed a revival of research in the interplay between cognition and emotion. Emotion theorists have recognized the pivotal role of cognitive factors in virtually all aspects of the emotion process. They rely on basic cognitive factors and insight in creating new models of affective space. Also, the successful application of cognitive therapies to affective disorders has prompted clinical psychologists to work towards a clearer understanding of the connections between cognitive processes and emotional problems. An analytical review of studies is presented to explain individual differences in cognitive achievement and emotional adaptation in adolescents. Gender differences, culture, and school environment are studied as independent variables. Development of cognitive psychology and neuroscience in the areas of cognitive and emotional behaviour made many contributions to the understanding of the positive and negative correlates of human behaviour, neural processes, and their implications in the daily lives of the people. Based on these new challenges and emerging nuances of positive psychology, the present paper deals with empirical data-based researches in the area of development of constructive cognition in shaping positive behaviour and healthy society.
\end{abstract}

Keywords: constructive cognition, emotion, behaviour adaptation, environment, neuroscience

\section{Introduction}

Understanding of human behaviour and its determinants had been a dominant area of research in psychology ever since the discipline has emerged as an independent science. It is evident that understanding of human behaviour is not possible through psychology alone but a multidisciplinary knowledge is required to focus on this complex subject.

Recent studies have reported that human behaviour is influenced by physical, psychological, and environmental factors. Research data on dynamics of human behaviour and its determinants are vast. To limit our discussion to the present theme, we would review those studies that indicate an association of multivariate variables and interplay between human brain, personality characteristics, and environmental situations.

The fact that human beings are social and unique in their behaviours is an accepted norm in psychology. In order to understand the interdependent linkage of human biology, psychological characteristics and cognition, it

Lipi Mukhopadhyay, Ph.D., professor, Indian Institute of Public Administration. 
is important to note some of the definitions of human learning from the fields of psychology, education, anthropology, and cognitive sciences.

Situations might be said to co-produce knowledge through activity. Learning and cognition are fundamentally situated. (Brown, Collins, \& Duguid, 1989)

Rather than a person being "in" an environment, the activities of person and environment are viewed as parts of a mutual-constructed whole. Put simply, the inside/outside relationship between person and environment is replaced by a part/whole relationship. (Bredo, 1994)

Situated cognition theory, by contrast, shifts the focus from the individual to the socio-cultural setting and the activities of the people within that setting. Knowledge accrues through the live practice of the people in a society. (Driscoll, 2004)

Understanding of "how people learn", it is believed by the contemporary research findings that learning involves social participation (Driscoll, 2004), and learning is an integral part of generative social practice in the lived in world (Lave \& Wenger, 1991).

Situated cognition acknowledges the mind-body connection. It focuses on "dynamics of intentions" where the individuals intentionally adopt a specific goal. The intention will direct and control the individuals' behaviour until the goal is achieved (Kugler, Shaw, Vicente, \& Kinsella-Shaw, 1991; Shaw, Kadar, Sim, \& Repperger, 1992; Young, Kulikowich, \& Barab, 1997).

According to Eysenck and Keane (2005) learning occurs in three stages: encoding, storage, and retrieval.

This view represents nature-nurture dichotomy which describes knowledge as either innate or experiential. A common metaphor for this type of knowledge is a computer. People and computers store information and process information sequentially in a number of steps. Learning is transferable to situation. Engle (2006) suggested that "Transfer is more likely to occur when learning contexts are framed as part of a larger ongoing intellectual conversation in which students are actively involved”. On knowledge "transfer", Collins, Brown, and Newman (1989) observed that,

Learning in multiple contexts induces the abstraction of knowledge, so that students acquire knowledge in a dual form, both tied to the contexts of its uses and independent of any particular context. This unbinding of knowledge from a specific context fosters its transfer to new problems and new domains.

It becomes evident from these discussions what makes people behave the way they do. Human learning takes place in the "real world". Thinking is complex, radical, individual yet inextricably bound to, and motivated by, the complex social human interaction (Wikipedia). Human thought and human action are the product of a dynamic interplay of personal, behavioural, and environmental influences (Pajares, 2005).

\section{Why Emotion Is Important in Cognition?}

Emotion and cognition are inseparable entity. They function in a continuum process. There is a good deal of research evidence now that there are almost constant interactions between cognition and emotion in everyday life. Interrelationship between neuroscience and development of children is found significant. It is reported that how children differ in their capacity to benefit from their early motor and cognitive experiences can be understood. The crucial roles of attention and memory were established in motor and perceptual development (Dalton \& Bergenn, 2007). It further claims that experience affects brain growth and a child's capacity to learn in neuro-science it is assured that "affect" and cognition compete for brain resources (Isen, 2003). Earlier it was believed that "affect" and cognition had separate forces and processes rooted in the 
psychological concepts: cognition, conation, and affect (Hilgard, 1980; Isen \& Hastorf, 1982; Isen, 2002). It is established by significant research findings that cognitive processing is involved in emotion.

An extensive research evidences indicate that positive "affect" has important facilitating effects on thinking and on people's ability to function. This is found among children, adult, and other professionals (Isen, 1999, 2002; Isen, Daubmn, \& Nowicki, 1987; Isen, Johnson, Mertz, \& Robinson, 1985; Isen, Rosenzweig, \& Young, 1991; Kahn \& Isen, 1993). The positive feedback strengthens self-esteem and motivates the individuals to put more attention to outer and inner sources of energy (Csikszentmihalyi, 2002). This was supported by positive psychologist, Seligman (2002), and consequent research evidences. It is reported that positive feeling is a neon, a potential to win by activating an expansive, tolerant, and creative mindset. Positive affect signals that a situation is benign, whereas negative affect indicates a problem (Schwarz, 1990).

People evaluate their behaviours and actions in a given environment based on the characteristics they possess and review and alter them if necessary for future actions. This is known as "reciprocal determinism" (Bandura, 1986). According to Bandura (1986), human behaviour is the result of: (1) personal factors-cognitive, affect, and biological; (2) behaviour and actions; and (3) environmental influences which create interactions that result in triadic reciprocality.

Actions are good indicators of emotion. Thus, it is possible to infer emotion from different aspects of action, both expressive and instrumental. Emotion can be detected and interpreted from facial expressions (Ohman, 2006). It is further reported that from different outputs such as verbal reports, physiological and behavioural changes it may provide clear understanding of emotion and its bearing on evolutionary theory and neuroscience. It is evident that positive emotion helps in constructive evaluation for achieving optimal results in a given task.

Defining the interrelated link between emotion and cognition modern research studies reported the impact of exposure and non-exposure state. It was found that participants were exposed to a set of Chinese ideograms very briefly so that they could not differentiate the ideograms. They were then shown and asked to rate the stimuli they had already viewed and stimuli to which they had not been exposed. Participants rated the previously exposed Chinese ideograms as more likeable than similar non-exposed ideograms (Zajonc, 1980). Emotion as sensory-motor reflexive as considered (James \& Lange, 1885; Cannon, 1927) and its critiques in subsequent researches showed autonomic nervous system as important device for emotional state. In a given situation, when emotional information reaches amygdale and starts activating the bodily response within some 10 milliseconds after reaching sensory receptors and before reaching the adequate cortical areas may produce emotion.

Cognitive role in emotion may be understood from research evidences that the brain may have quite specific information from the body early enough to make a factor in shaping emotional experience. Recalling certain emotional episodes sets off distinct patterns of activity in brain structures that regulate and represent bodily states—-patterns that differ between emotions (Damasio, 1999). This suggests that emotion is a matter of reflection. People to a considerable extent construct their emotions. It is also found that the perceived meaning of the situation is the "central determinant" of the emotional response and the meaning the respondents claim results from an "appraisal” process (Ohman, 2006).

\section{Cognitive Determinants of Emotion}

Most cognitive psychologists ignore the issue of the effects of emotion on cognition. But with extensive 
research done in the areas of "emotional states" (Lazarus, 1991; Smith \& Lazarus, 1993), factors determining emotion have been stated (Parkinson, 1994) as appraisal of some external situations, reactions of the body, facial expression, and action tendencies. It is defined that "Emotions are an integral and central component of human functioning and affairs in everyday life” (Cigrrochi, Forgas, \& Mayer, 2006).

It is important to note that these four factors are not independent of each other. In fact, cognitive appraisal of the situation, affects, bodily reactions, facial expression, and action tendencies influence emotional experience. This research inspired the bold notion that cognitive factors, especially, appraisals are always of fundamental importance in determining emotional experience (Lazarus, 1982; 1991).

\section{Gender Difference in Cognition and Emotion}

A vast literature is available to understand the gender difference in cognitive and emotional behaviours. It found that men and women differ in emotional intelligence. A worldwide study of $(500,000)$ people by Bradberry and Su revealed significant differences in overall emotional intelligences and three of the four emotional intelligence skills. Men and women were measured on: self-awareness, self-management, social-awareness, and relationship management.

Women outscored men in all the skills except self-awareness. This is important to note that on self-awareness men and women received equal score.

Another study was done on knowledge and attitude towards mental health and people with mental health problems measured among 496 boys and girls (teenagers) reported by Williams and Janette (2007). It was found that boys reported lower levels of knowledge and different sources of stress than girls. Negative attitudes were more common among boys than girls. Boys were less likely to think that an understanding of mental health was important.

An ongoing research study on “adolescents' strengths” indicated (pilot study) gender difference between male and female students. It was found that female students have more humility, perseverance, and integrity whereas males showed curiosity of learning and optimism (Mukhopadhyay, 1998). Another study has indicated that gender identity develops through the process of a lifetime of learning experiences (Mukhopadhyay, 1998).

From the above discussion, it is established that emotion plays a crucial role in cognition. But how do individuals learn, store information, remember and recall them, what kind of neural processing takes place in the brain in daily learning, and how do they change, make new neurons and synaptic connections, are still not known fully.

Neuroscientists jointly with other related branches of science are constantly trying to evolve more scientific information on brain and behaviour dynamics. It is a difficult and challenging task as we know that the mind is not just a passive encoder of reality. The brain is continually organizing, structuring, extracting, and creating. As a result of learning, brain comes to recognize a stimulus as a signal of vulnerable and disaster. For example, during Tsunami in the year 2004, Onge tribal community of Andaman and Nicobar Island got the signal of disaster prior to others to save their life on time (Mukhopadhyay, 2005).

Recent developments of cognitive and neuroscience in the areas of positive emotion and cognitive development need to be highlighted as significant contribution towards human learning and behaviour modification. Positive beliefs about self provide the foundation for motivation. This was well documented by Pajares (2005). He defined self-efficacy as "These self-efficacy beliefs provide the foundation for motivation, well-being and personal accomplishment in all areas of life". This states that if the individuals believe that their 
action will produce desired results then they will make efforts and be motivated to accomplish the goal. There has been noteworthy contribution made on this concept by others (Goleman 1993; Seymour Epstein; Gardner 2003; Snyder \& Loopez, 2005; Bandura, 1997; Zimmerman, 2003). It is found that positive emotion promotes well-being and social responsibility (Isen, 1987). Researches on positive emotion showed that positive emotion often facilitates cognitive processing (Forgas, 2002; Schwarz \& Bless, 1991).

\section{Discussion}

Shaping constructive cognition with positive values in the children is particularly important, as their brain is still plastic, receptive, and free from prejudice. For enhancing academically, the students should be focused on developing right skills for accomplishment. Parents and school teachers can work out how to build desired skill to enhance knowledge towards developing self-confidence and esteem among young adolescents. Students' self-efficacy beliefs develop primarily through actual success on challenging academic tasks. Similar views were expressed by Erik Erikson (1959) that "Ego identity gains real strength only from wholehearted and consistent recognition of real accomplishment that is achievement that has meaning in their culture”.

It is important to remind the educationists that characteristics of successful individuals do not undermine their self-efficacy beliefs in the face of failure and adversity. In fact, young children should be taught that failure is normative and building resilience is an important trait. Another way of building positive behaviour in the school culture is to make the classroom and school environment facilitate students' competencies in normal standardized academic atmosphere without competitive and individualized manner. The school atmosphere should help students develop a cooperative and persuasive personality engaging in learning and flourishing. In classroom, teachers should be careful in instruction and making comments toward some students that may affect the healthy peer relationship. In group activity, often, teachers are not careful about the selection of students and personality which may be a disadvantage for others and only a few would dominate and monopolize the activity. It should be ensured that everybody participates in such group activities irrespective of their competences.

Praise and appreciation for good work may be made honestly when they deserve. One of the ways to praise a deserving task or a performance is the recognition of the effort and encouragement and ensuring support may go a long way to develop positive self-esteem among young children.

\section{Foster Optimism and Confidence}

Optimism refers to adaptive behaviour, learning aptitude, positive goal setting, and use of opportunity for optimal use. These characteristics are usually demonstrated in everyday life at home and school. Parents and teachers may make room to develop such characteristics among their children and students. It is found that an environment of less competitive on "success" but on developing "competence” may foster self-confidence and adaptability among young children. Research studies have been reported on how low self-efficacy was found to be related to maladaptive academic behaviours, disciplinary problems and school drop-outs irrespective of knowledge and skill (Pajares, 2005). Critical challenge of parents and educators is making children's self-regulatory practices as early as possible (William James, 1985). According to James, self-regulatory processes that individuals use to make most of their decisions become automatic and are exercised primarily unconsciously. These habitual ways of behaving are a powerful influence on the choices that people make on the success or failure they experience. 
Once self-efficacy beliefs are cognitively structured across activities the effect of such beliefs may be generalized. For example, students not good at mathematics may be made to believe that increased effort and perseverance will result in academic progress and greater understanding in the "subject". The connection will be made to achieve success in other academic areas.

\section{Conclusion}

As discussed earlier that emotion is an integral part of cognition and motivational process. It is convincing to believe that more positive emotional experiences will broaden and build the perspectives of an individual seeking goal attainment (Fredrickson, 2001). Multiple intelligences embodied in biological potential and environmental factors need constructive cognition and interactive resources to develop in early childhood (Gardner, 1993). It is possible to identify a special domain of interest or potential out of other abilities among the children enabling them to master in that specific domain. Fostering values among young children addressing gender issues, caste, class stereotypes, communal violence towards harmonious and healthy society may be built through conscious effort by all the stakeholders in respective fields.

Researches on "emotional states" suggest that facts determining emotions are the appraisal of some external situations, reactions of the body, facial expressions and actions.

\section{References}

Bradberry, T., \& Su, L. D. (2007). Women feel smarter. Retrieved from http://www.Talentsmart.com

Bandura, A. (1986). Social cognitive theory: A framework for therapeutic recreation. Therapeutic Recreation Journal, Fourth Quarter, 2002.

Bredo, E. (1994). Reconstructing educational psychology: Situated cognition and pragmatism. Educational Psychologist, 29(I), 23-35.

Brown, J. S., Collins, A., \& Duguid, S. (1989). Situated cognition and the culture of learning. Educational Researcher, 18(I), $32-42$.

Cigrrochi, J., Forgas, J. P., \& Mayer, J. D. (2006). Emotional intelligence in everyday (2nd ed.). Psychological Press.

Clancey, W. J. (1993). Situated action: A neuropsychological interpretation response to vera and simon. Cognitive Science, 17, 87-116.

Collins, A., Brown, J. S., \& Newman, S. E. (1989). Cognitive apprenticeship: Teaching the crafts of reading, writing, and mathematics. In L. B. Resnick (Ed.), Knowing, learning, and instruction: Essays in honor of Robert Glaser (pp. 453-494). Hillsdale, N. J.: Lawrence Erlbaum Associates.

Csikszentmihalyi, M. ( 2002). Flow: The psychology of optimal experience. Harper.

Dalton, T. C., \& Bergenn, V. W. (2007). Early experience, the brain and conciousness. Lawrence Erlbaum Assocites,Taylor and Francies.

Damasio, A. (1999). The feeling of what happens, body and emotion in the making of consciousness. New York: Harcourt Brace.

Driscoll, M. P. (2004). Psychology of learning for instruction. Upper Saddle River, N. J.: Allyn \& Bacon.

Engle, R. A. (2006). Framing interactions to foster generative learning: A situative explanation of transfer in a community of learners classroom. Journal of the Learning Sciences, 15(4), 451-498.

Epstein, S. (n.d.). Constructive thinking: The key to emotional intelligence. Retrieved from http://www. Amazon.com

Erikson, E. (1959). Identity and the life cycle. Psychological Issues, BF21, P7, 1959X. New York: International Universities Press.

Eysenck, M. W., \& Keane, M. T. (2005). Cognitive psychology (Vol. 5). Psychology Press.

Forgas, J. P. (2002). Feeling and doing: Affective influences on interpersonal behaviour. Psychological Inquiry, 13, 1-28.

Fredrickson, B. L. (2001). The role of positive emotions in positive psychology. American Psychologist, 56(i), 215-226.

Hilgard, E. R. (1980). The trilogy of mind: Cognition, affection and conation. Journal of the History of the Behavioural Science, $16,107-117$. 
Isen, A. M. (1999). On the relationship between affect and creative problem solving. In Russ (Ed.), Affect, creative experience, and psychological adjustment (pp. 3-17). Philadelphia: Taylor and Francis.

Isen, A. M. (2000). Positive affect and decision-making. In M. Lewis, \& J. M. Haviland-Jones (Eds.), Handbook of emotions (2nd ed., pp. 417-435). New York: Guilford Press.

Isen, A. M. (2002). Missing in action in the AIM: Positive affects facilitation of cognitive flexibility, innovation and problem solving. Psychological Inquiry, 13, 57-65.

Isen, A. M. (2003). A psychology of human strengths. Aspinwall and Ursula Staudinger.

Isen, A. M., Daubmn, K. A., \& Nowicki, G. P. (1987). Positive affect facilitates creative problem solving. Journal of Personality and Social Psychology, 52, 1122-1131.

Isen, A. M., \& Hastorf, A. H. (1982). Some perspectives on cognitive social psychology. In A. H. Hastorf, \& A. M. Iisen (Eds.), Cognitive social psychology (pp. 1-31). New York: Elsevier Worth Holland.

Isen, A. M., Johnson, M. M., Mertz, E., \& Robinson, F. G. (1985). The influence of positive affect on the unusualness of word association. Journal of Personality and Social Psychology, 48, 1413-1426.

Isen, A. M., Rosenzweig, A. S., \& Young, M. J. (1991). The influence of positive affect on clinical problem solving, medical decision making (Vol. 11, pp. 221-227).

James, W. (1885). What is an emotion? Mind , 9, 188-205.

Kahn, B., \& Isen, A. M. (1993). The influence of positive affect on variety seeking among safe, enjoyable products. Journal Consumer Research, 20, 257-270.

Kugler, P. N., Shaw, R. E., Vicente, K. J., \& Kinsella-Shaw, J. (1991). The role of attractors in the self-organisation of intentional systems. In R. R. Hoffman, \& D. S. Palermo (Eds.), Cognition and the symbolic processes. Hillsdale, N. J.: Erlbaum.

Kunst, W., Wilson, \& Zajone, R. (1980). Affective discrimination of stimuli that cannot be recognized. Science, 207, 557-558.

Lave, J., \& Wenger, E. (1991). Situated learning: Legitimate peripheral participation. Cambridge: University of Cambridge Press.

Lazarus, R. S. (1991). Although the various structural appraisal models differ in a number of respects. In M. A. Hogg, \& J. Cooper (Eds.), The handbook of social psychology. Sage Publication.

Melton, R. J. (1995). The role of positive affect in syllogism performance. Personality and Social Psychology Bulletin, 21, 788-794.

Mukhopadhyay, L. (1998). Women: The search for identity. Social Welfare, 44(10), 4-7.

Mukhopadhyay, L. (n.d.). Positive and collectivist traits among tribal community: Case study (Unpublished thesis).

Ohman, A. (2006). Making sense of emotion: Evolution, reasons and the brain. Daedalus, 133(1).

Pajares, F. (2005). Self efficacy beliefs of adolescents (pp. 339-367). Information Age Publishing Inc.

Schwarz, N., \& Bless, H. (1991). Happy and mindless, but sad and smart? The impact of affective states on analytic reasoning. In J. P. Forges (Ed.), Emotion and social judgment (pp. 55-71). Oxford, England: Perganon.

Seligman, M. E. P. (2002). Authentic happiness. New York: Free Press.

Shaw, R. E., Kadar, E., Sim, M., \& Repperger, D. W. (1992). The intentional spring: A strategy for modeling systems that learn to perform intentional acts. Journal of Motor Behavior, 24(1), 3-28.

Smith, C. A. (1993). Cognition and motivation in emotion. In Handbook of social psychology. Sage Publication.

Snyder, C. R., \& Loopez, S. J. (2005). Scientific and practical explorations of human strengths. Retrieved from http://www. Amazon.com

Williams, B. Y., \& Janette, P. (1007). Gender differences and mental health: An exploratory study of knowledge and attitudes to mental health among scottish teenagers child and adolescent mental health. Child and Adolescent Mental Health, 12(1), 8-12.

Young, M. F., Kulikowich, J. M., \& Barab, S. A. (1997). The unit of analysis for situated assessment. Instructional Science, 25(2), 133-150.

Zajone, R. (2006). Journal of Personality and Social Psychology Monograph Supplement, 9(2), 1-27.

Zimmerman, B. J., \& Schunk, D. H. (2003). Albert Bandura: The scholar and his contributions to educational psychology. In B. L. Zimmerman, \& D. H. Schunk (Eds.), Educational psychology: A century of contributions (pp. 431-458). Mahwah, N. J.: Erlbaum. 